\title{
Nanofluid of zinc oxide nanoparticles in ionic liquid for single drop liquid microextraction of fungicides in environmental waters prior to high performance liquid chromatographic analysis
}

\author{
Meseret Amde ${ }^{\mathrm{a}, \mathrm{b}}$, Zhi-Qiang Tan ${ }^{\mathrm{a}}$, Rui Liu ${ }^{\mathrm{a}}$, Jing-Fu Liu ${ }^{\mathrm{a}, *}$ \\ a State Key Laboratory of Environmental Chemistry and Ecotoxicology, Research Center for Eco-Environmental Sciences, Chinese Academy of Sciences, \\ P.O. Box 2871, Beijing 100085, China \\ b School of Chemistry and Chemical Engineering, University of Chinese Academy of Sciences, Beijing 100049, China
}

\section{A R T I C L E I N F O}

\section{Article history:}

Received 29 January 2015

Received in revised form 20 March 2015

Accepted 20 March 2015

Available online 28 March 2015

Keywords:

Fungicides

Nanofluid

Single drop microextraction

High performance liquid chromatography

Water samples

\begin{abstract}
A B S T R A C T
Using a nanofluid obtained by dispersing ZnO nanoparticles (ZnO NPs) in 1-hexyl-3-methylimidazolium hexafluorophosphate, new single drop microextraction method was developed for simultaneous extraction of three fungicides (chlorothalonil, kresoxim-methyl and famoxadone) in water samples prior to their analysis by high performance liquid chromatography (HPLC-VWD). The parameters affecting the extraction efficiency such as amount of ZnO NPs in the nanofluid, solvent volume, extraction time, stirring rate, $\mathrm{pH}$ and ionic strength of the sample solution were optimized. Under the optimized conditions, the limits of detection were in the range of $0.13-0.19 \mathrm{ng} / \mathrm{mL}$, the precision of the method assessed with intra-day and inter-day relative standard deviations were $<4.82 \%$ and $<7.04 \%$, respectively. The proposed method was successfully applied to determine the three fungicides in real water samples including lake water, river water, as well as effluent and influent of wastewater treatment plant, with recoveries in the range of $74.94-96.11 \%$ at $5 \mathrm{ng} / \mathrm{mL}$ spiking level. Besides to being environmental friendly, the high enrichment factor and the data quality obtained with the proposed method demonstrated its potential for application in multi residue analysis of fungicides in actual water samples.
\end{abstract}

(c) 2015 Elsevier B.V. All rights reserved.

\section{Introduction}

Pesticides are used at various stages in agricultural process to boost the harvesting products. Therefore, contamination of matrices such as soil, water and even the agricultural products with various agrochemicals is a serious threat to human health $[1,2]$. Owing to properties like high stability and resistant to a wide range of $\mathrm{pH}$, temperature and light, fungicides, one type of pesticides, are widely used for the protection and preservation of a variety of crops, fruits, and vegetables [3]. Fungicides are directly applied to the agricultural soils or sprayed on the field crops [4,5], and hence can easily release away from the application sites by air or rain water and contaminate water bodies. European Union Directive set the maximum allowed concentration of individual and total pesticides to be 0.1 and $0.5 \mathrm{ng} / \mathrm{mL}$, respectively on the quality of water intended for human consumption [6]. Therefore, preconcentration techniques are required to investigate fungicides at trace levels.

\footnotetext{
* Corresponding author. Tel.: +86 10 62849192; fax: +86 1062849192.

E-mail address: jfliu@rcees.ac.cn (J.-F. Liu).
}

There are numerous preconcentration techniques like solidphase microextraction (SPME) [7-9], dispersive liquid-liquid microextraction (DLLME) [10-12], hollow fiber liquid phase microextraction (HF-LPME) [13], salting-out assisted liquid-liquid extraction [14], ultrasound-assisted emulsification microextraction [15,16], cloud point extraction [17] for the determination of fungicides in water samples. SPME is simple, solvent free and a technique in which efficient extraction is possible. The draw backs of SPME are cost of analysis, analyte carry-over, limited life time due to fiber-fragility and long analysis time. DLLME is the other microextraction technique which is cheap, simple, fast and present high enrichment factor. But difficulty to automation and requirement of environmentally unfriendly extraction solvents are its limitations. HF-LPME is also a simple and inexpensive technique in which high analyte preconcentration and excellent sample cleanup is possible. But, its limitations like long analysis time and memory effect when reusing the hollow fiber could be stated. Even though the use of microextraction techniques decrease environmental impact and the exposure of personnel to solvent vapors $[18,19]$ most of these approaches directly or indirectly consume significant amount of organic solvents which can cause different toxicological problems. Hence, using either relatively green solvents 
or further reducing the amount of these solvents for the intended purpose is still interesting scientific research. Single drop microextraction (SDME) is liquid-liquid microextraction technique in which the amount of extraction solvent is drastically reduced. It is simple, inexpensive, easy to operate, versatile, and has additional qualities like different extraction modes, high enrichment factor and can be fully automated [18]. However, instability and ease of dislodgment of the micro-drop, limited drop volume, and evaporation of the micro-drop due to its volatility and low viscosity are the main problems associated to SDME. To overcome these limitations, investigation of suitable mode of SDME and appropriate solvent (viscous and non-volatile) which can form stable, relatively large drop volume with high extraction quality is required.

Metal oxide nanoparticles (NPs) have attracted considerable attention for their potential application in many technologies [20]. ZnO nanoparticles (ZnO NPs), one of the metal oxide NP, was employed for extraction purpose. Ghaedi et al. [21] used ZnO NPs loaded on activated carbon for efficient extraction of brilliant green dye and for removal of bromophenol red [22] in aqueous solutions. It was also applied as solid-phase adsorbent and as efficient solar photo-catalyst [23]. Wang and his co-authors employed silver NPs decorated ZnO NP sheets as effective surface enhanced Raman scattering substrate and applied for rapid detection of organic pollutants [24]. Besides, preparation and characterization of $\mathrm{ZnO}$ nanofluids ( $\mathrm{ZnO}-\mathrm{NFs}$ ) and its applications have been reported [25-28].

Nanofluids (NFs) are materials comprising of stable suspensions of NPs $(<100 \mathrm{~nm})$ in base fluids [29] which can be prepared in different ways [30]. NFs have wide applications in various scientific areas. Suspending small amount of NPs in liquid-liquid system can cause considerable augmentation in mass transfer coefficient, and hence expected to improve the extraction efficiency which is of great interest in recent. A recent review provided the unique liquid-liquid properties, fundamental technologies and NFs application in chemical and bio-analysis methods and devices [31]. Krishnamurthy et al. obtained faster diffusion of a dye droplet in water based NF than in pure water [32]. Fang et al. also observed mass diffusion of rhodamine $\mathrm{B}$ to be about 10.71 times in $0.5 \% \mathrm{Cu}$ NFs than in water alone [33]. The application of NFs to modify the mass transfer coefficient in extraction processes has been reported in recent. Above $121 \%$ enhancement in the rate of mass transfer was reported upon adding $0.002 \%$ modified $\mathrm{Fe}_{3} \mathrm{O}_{4}$ and $\mathrm{Al}_{2} \mathrm{O}_{3} \mathrm{NPs}$ to a single drop in liquid-liquid extraction process [34]. The use of NFs to enhance the performance of a pulsed liquid-liquid extraction column was investigated and addition of $0.01-0.1 \%(v / v) \mathrm{SiO}_{2}$ NPs to kerosene increased the mass transfer by a factor of $4-60 \%$ [35]. The same research group obtained 60\% improvement in mass transfer performance by adding $0.1 \%(\mathrm{v} / \mathrm{v}) \mathrm{SiO}_{2}$ to kerosene-acetic acid-water chemical system in pulsed liquid-liquid extraction column [36].

Ionic liquids (ILs) are compounds containing exclusively of ions, usually organic cations and organic/inorganic anions [37]. Even though ILs are considered as green alternates to volatile and toxic organic solvents, the issue of their potential biological toxicities has been reported [38-40]. However, due to their astonishing characteristics, ILs have wide application in several aspects of scientific work including as advantageous solvents for sample pretreatment [41]. The application of nanocomposites of different types of NPs and ILs has been reported in recent. Pena-Pereira et al. used nanoconfined IL-rich fibers in headspace SPME of volatile aromatic compounds and obtained high enrichment factors (up to 7400) and low LOD values $(0.03-1.27 \mathrm{ng} / \mathrm{mL})$ [42]. Ternary composites of nanocellulose, carbonanotubes and ILs exhibited excellent extraction efficiency than the corresponding pure ILs in direct immersion SDME of heterocyclic amine [43]. Therefore, combination of ILs and
NPs in the form of IL-NFs may impart certain additional properties to the ILs. In addition, the aforementioned studies are indicators for the possibility of ILs based NFs consumption as extraction solvents for trace analysis of environmental pollutants.

The purpose of this study was to prepare stable 1-hexyl3-methylimidazolium hexafluorophosphate ([HMIM][PF 6$]$ ) based $\mathrm{ZnO}-\mathrm{NF}$ for its application in a modified direct immersion single drop microextraction (SDME), namely ZnO-NF-based SDME (ZnONF-SDME), for enrichment of fungicides in water samples. The preferences of $\mathrm{ZnO}-\mathrm{NF}$ for the investigation were initiated from the fact that unlike many metallic NFs, ZnO-NF form stable suspension without additional stabilizers due to the surface charges on $\mathrm{ZnO}$ NPs. The stability is crucial for its application in different areas like in extraction procedures. In addition to these, the use of ZnO-NF as a replacements of other organic solvents is relatively non-toxic and it allow the use of large drop volume due to its high viscosity and stability. Furthermore, ZnO-NF-SDME would exhibit higher enrichment factor which would be practically helpful to extract the target analytes at very trace level.

\section{Experimental}

\subsection{Chemicals and reagents}

Zinc nitrate hexahydarate $\left(\mathrm{Zn}\left(\mathrm{NO}_{3}\right)_{2} \cdot 6 \mathrm{H}_{2} \mathrm{O}\right)$ (AR grade), sodium hydroxide $(\mathrm{NaOH})$ (AR grade) and sodium chloride $(\mathrm{NaCl})$ (GR grade) were obtained from Sinopharm Chemical Reagent Co., Ltd. (Shanghai, China). 1-Butyl-3-methylimidazolium tetrafluoroborate ([BMIM] $\left.\left[\mathrm{BF}_{4}\right]\right)$ and 1-hexyl-3-methylimidazolium hexafluorophosphate ([HMIM] $\left.\left[\mathrm{PF}_{6}\right]\right)$ were purchased from Aladdin Industrial Corporation (Shanghai, China). Kresoxim-methyl and famoxadone standards (Purity $>98 \%$ ) were purchased from Dr. Ehrenstorfer $\mathrm{GmbH}$ (Augsburg, Germany), while chlorothalonil (Purity, 99.7\%) was obtained from AccuStandard, Inc. (New Haven, USA). The physicochemical characteristics of these fungicides are shown in Table 1. HPLC grade acetonitrile and methanol solvents were obtained from Fisher Scientific (New Jersey, USA). Ultrapure water prepared by a Milli-Q Gradient system (Millipore, Bedford, MA, USA) was used throughout the experiments

\subsection{Preparation and characterization of ZnO NPs}

For the preparation of ZnO NPs, the sol-gel process reported by Gandhi et al. [44] was followed with minor modifications. In detail, $50 \mathrm{~mL}$ of $0.4 \mathrm{~mol} / \mathrm{L} \mathrm{Zn}\left(\mathrm{NO}_{3}\right)_{2} \cdot 6 \mathrm{H}_{2} \mathrm{O}$ solution was prepared in water and mixed with $1 \mathrm{~mL}$ of [BMIM][BF $]$ to obtain colorless and transparent solution up on vigorous stirring. Freshly prepared $30 \mathrm{~mL}$ of $\mathrm{NaOH}(0.8 \mathrm{~mol} / \mathrm{L})$ was added in drops under magnetic stirring to obtain precursor $\mathrm{Zn}(\mathrm{OH})_{2}$ sol and further stirred for another $2 \mathrm{~h}$ at room temperature. The obtained $\mathrm{Zn}(\mathrm{OH})_{2}$ sol was allowed to stand overnight and the supernatant liquid was discarded. The settled precursor was recovered by centrifugation at $10,000 \mathrm{rpm}$ for 15 min followed by washing with water and ethanol several times to remove any aggregates and organic impurities and then vacuum dried at $80^{\circ} \mathrm{C}$. The dried $\mathrm{Zn}(\mathrm{OH})_{2}$ precursor was grinded and calcined at $300^{\circ} \mathrm{C}$ to obtain crystallized ZnO NPs.

The size and morphology of the ZnO NPs were characterized by transmission electron microscopy (TEM; H-7500, Hitachi). Xray diffraction (XRD) analysis was performed with an X'pert PRO instrument (PANalytical) using $\mathrm{Cu}-\mathrm{K} \alpha$ radiation. Effective removal of the NPs from the extractant before HPLC system was confirmed by recording UV-vis spectra with Shimadzu UV-3600 (Kyoto, Japan) in separate experiment. 
Table 1

Physicochemical properties of the target fungicides.

\begin{tabular}{|c|c|c|c|c|c|c|}
\hline Common name & Abbr. & Chemical structure & CAS no. & $\begin{array}{l}\text { Molecular } \\
\text { weight }(\mathrm{g} / \mathrm{mol})\end{array}$ & $\begin{array}{l}\text { Water solubility } \\
(\mathrm{mg} / \mathrm{L})\end{array}$ & $\log K_{\text {ow }}\left(25^{\circ} \mathrm{C}\right)$ \\
\hline Chlorothalonil & CLT & & $1897-45-6$ & 265.91 & $0.6-1.2^{a}$ & 2.92 \\
\hline Kresoxim-methyl & KSM & & $143390-89-0$ & 313.36 & $2^{\mathrm{b}}$ & 3.40 \\
\hline Famoxadone & FMX & & $131807-57-3$ & 374.39 & $0.052^{\mathrm{b}}$ & 4.65 \\
\hline
\end{tabular}

a Values at $25^{\circ} \mathrm{C}$

b Values at $20^{\circ} \mathrm{C}$

\subsection{Preparation of IL-ZnO-NFs}

Two-step NF preparation method, which is suitable for metal oxide NPs based NF [34], was used in the preparation of ILs-ZnONFs. Accordingly, the synthesized ZnO NPs powder was dispersed in [HMIM] $\left[\mathrm{PF}_{6}\right]$ and hand shaken for homogeneous distribution of the NPs. The NFs were sonicated for 90 min to break up any potential clusters of the NPs. To monitor the stability and extraction performance of the NFs which might be affected due to variation of the amount of NPs, ZnO NPs was used with concentrations of 0.005 , $0.01,0.1,0.5$, and $1.0 \%(\mathrm{~m} / \mathrm{m})$.

\subsection{ZnO-NF-SDME procedure}

For the ZnO-NF-SDME procedure, a syringe tip cap (tip protector) of $5 \mathrm{~mL}$ disposable syringe (Shandong Weigao Group, Medical Polymer Company Limited, Shandong, China) passed through screw capped vial cap, were used in place of syringe needle and the rest procedure is same as conventional SDME. In detail, $10 \mu \mathrm{L} \mathrm{IL-ZnO-}$ NFs micro-drop was carefully placed on tip of the syringe cap, initially made after passing through the vial cap, and immersed in to $20 \mathrm{~mL}$ extraction vial containing $10 \mathrm{~mL}$ of the sample solutions spiked with the target analytes and magnetic stirring bar. All vials were tightly sealed, placed in a stirring plate and were kept stirring ( $500 \mathrm{rpm}$ ) at $25^{\circ} \mathrm{C}$ for $40 \mathrm{~min}$. After the extraction, the micro-drop was carefully deposited in an Eppendorf vial containing $100 \mu \mathrm{L}$ methanol followed by sonication for $10 \mathrm{~min}$, and posterior centrifugation ( $7000 \mathrm{rpm}, 10 \mathrm{~min}$ ) for complete removal of the NPs which was confirmed by recording its UV-vis spectra in separate experiment (data not shown). Then, $20 \mu \mathrm{L}$ of the extracted solution was injected to HPLC for determination of the fungicides. The whole $\mathrm{ZnO}-\mathrm{NF}-\mathrm{SDME}$ procedure is schematically shown in Fig. 1.

\subsection{HPLC analysis}

An Agilent 1200 HPLC system (Agilent Technologies, Santa Clara, CA, USA) equipped with a quaternary pump, vacuum degasser, variable wavelength detector and manual injector was employed to perform chromatographic analysis. An Agilent TC-C18 column $(250 \mathrm{~mm} \times 4.6 \mathrm{~mm}$ i.d., particle size $5 \mu \mathrm{m})$ was used for separation of the analytes. Data acquisition and processing were achieved using Agilent LC ChemStation software (Rev.B.03.01) throughout the analysis. Acetonitrile and water (60:40, v/v) mixture was delivered at a flow rate of $1.0 \mathrm{~mL} / \mathrm{min}$ in isocratic mode as the mobile phase. The detection wavelength was initially held at $229 \mathrm{~nm}(0-12.5 \mathrm{~min})$ for chlorothalonil, $225 \mathrm{~nm}$ (12.5-14.5 min) for kresoxim-methyl, and finally $229 \mathrm{~nm}$ (14.5-20 min) for famoxadone. The sample volume of $20 \mu \mathrm{L}$ was manually injected, and all the analytes were eluted over an $18 \mathrm{~min}$ and a 2 min post run time to allow the system to equilibrate prior to the next analysis. For all the target analytes, baseline separation was obtained under these chromatographic conditions and the peak area was used as an instrumental response for quantification. The quantification of the pesticides was performed by external calibration with mixed standard solutions, using 10 calibration points.
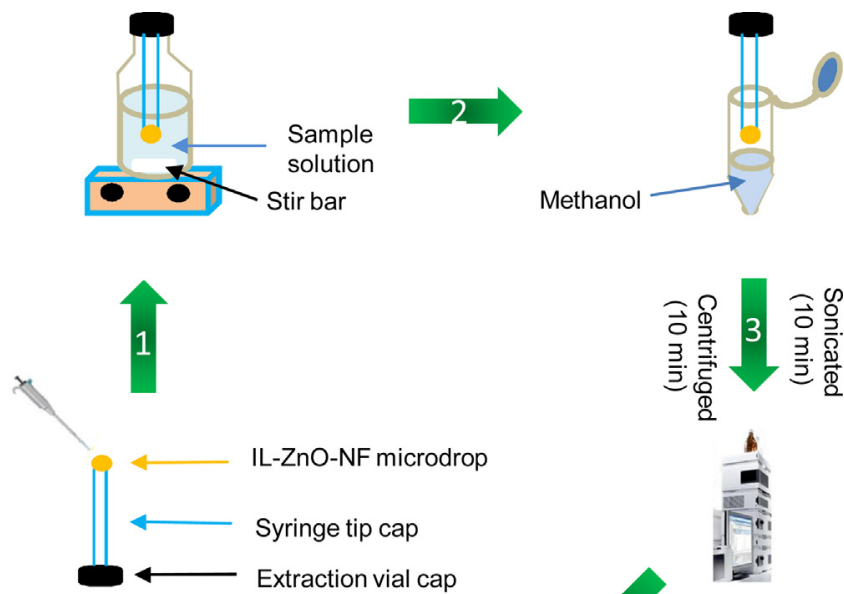

\section{IL-ZnO-NF microdrop}

Syringe tip cap

Extraction vial cap
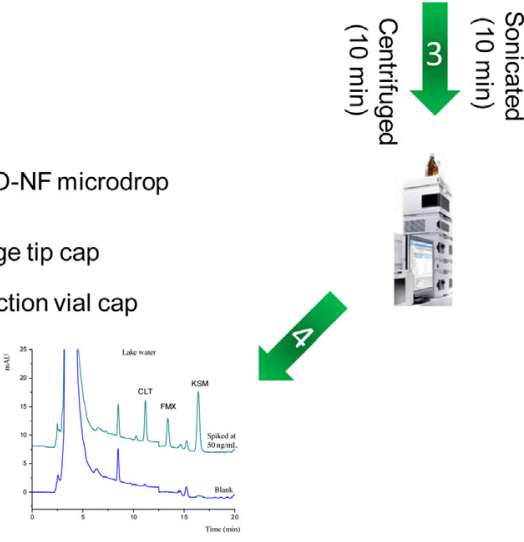

Fig. 1. Schematic representation of $\mathrm{ZnO}-\mathrm{NF}-\mathrm{SDME}$. 


\subsection{Sample collection}

Lake water sample was collected from Weiming Lake located in Peking University (Beijing, China), river water was collected from Chaobai River (Beijing, China), and sewage waste effluent and influent water samples were collected from Qinghe wastewater treatment plant (Beijing, China). The samples were filtered with $0.22 \mu \mathrm{m}$ micropore membrane and stored at $4{ }^{\circ} \mathrm{C}$ until analysis time.

\subsection{Quality assurance/quality control ( $Q A / Q C)$}

The sample solutions were stored in amber glass bottles to protect the possible loss of target analytes during storage. All the glassware and the magnetic stir bars were washed, oven dried and rinsed with acetone before use. Blank samples were investigated passing through the whole extraction procedure parallel to the samples in all experiments. The retention times of the target analytes in each of the standard solutions were used for HPLC peak identification and the analytes in the sample solutions. Method validation was investigated under optimal extraction conditions. The target fungicides were quantitatively determined using 10 external calibration points. Linearity of the method was obtained by investigating water samples spiked with concentration range of the fungicides from 0.5 to $100 \mathrm{ng} / \mathrm{mL}$. The limits of detections (LODs) and limits of quantifications (LOQs) were calculated on the basis of signal to noise ratios of $3(\mathrm{~S} / \mathrm{N}=3)$ and $10(\mathrm{~S} / \mathrm{N}=10)$, respectively. Intra-day and inter-day relative standard deviation (RSDs) at eight replicates $(n=8)$ investigated with water samples

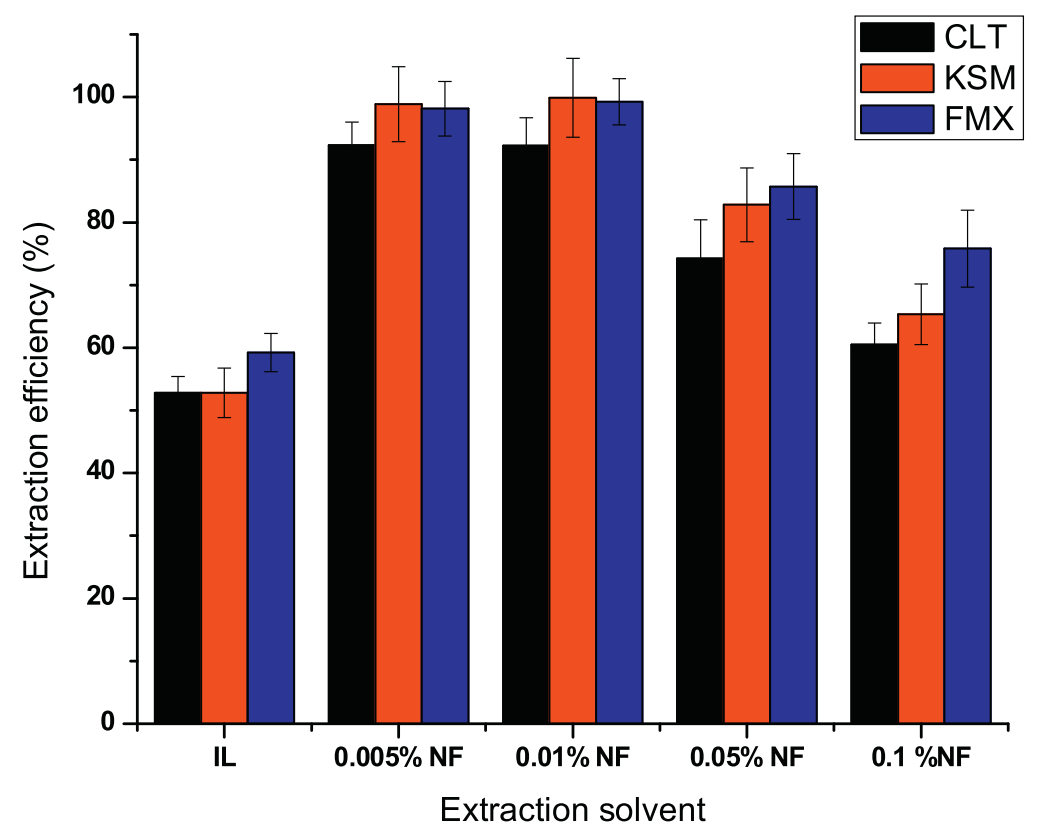

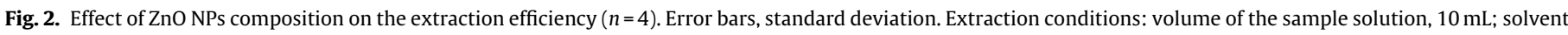
volume, $10 \mu \mathrm{L}$; extraction time, $40 \mathrm{~min}$; and stirring rate, $500 \mathrm{rpm}$.

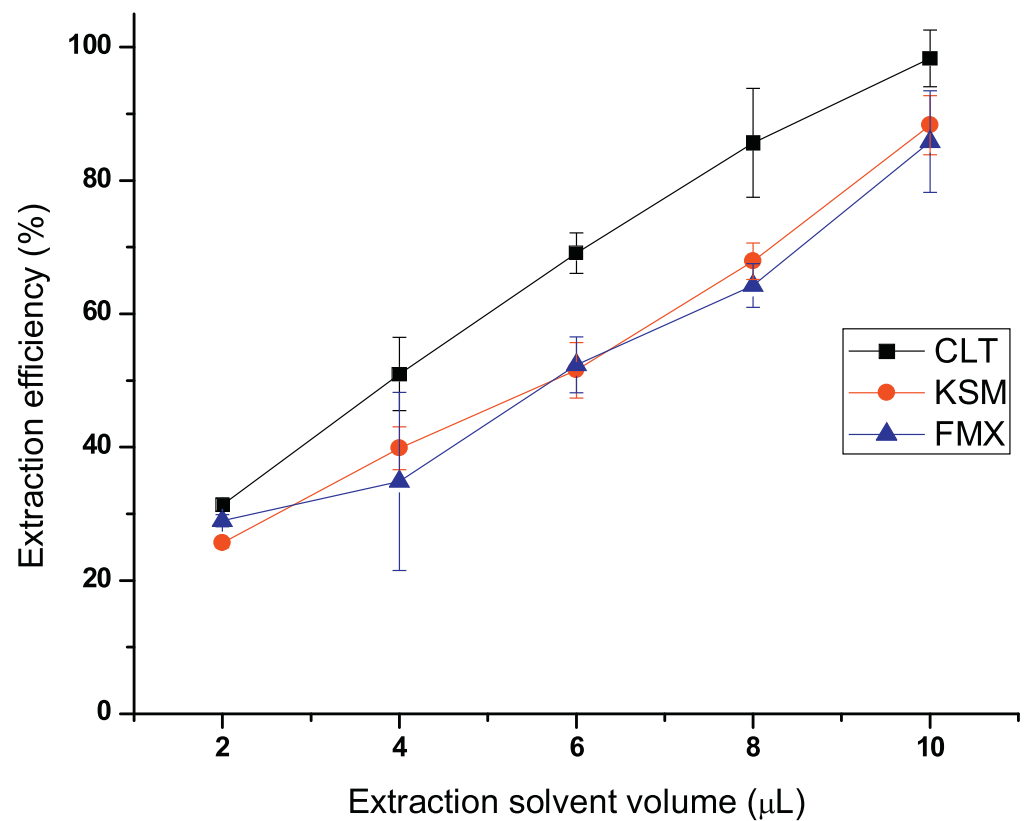

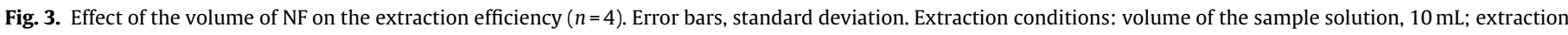
time, $40 \mathrm{~min}$; and stirring rate, $500 \mathrm{rpm}$. 
containing $5 \mathrm{ng} / \mathrm{mL}$ of the fungicides were used to evaluate the precision of the method. The robustness of the method in different waters was reflected by the recoveries determined for four different water samples (lake, river, effluent and influent) spiked at 5 and $100 \mathrm{ng} / \mathrm{mL}$.

\section{Results and discussion}

\subsection{Characterization of the $\mathrm{ZnO} N \mathrm{NS}$}

TEM images of the synthesized ZnO NPs were collected to characterize the size distribution of the materials as presented in supporting information (Fig. S1a). The particles sizes were computed with Nano Measurer software (version, 1.2) from the TEM images. The average size of the calcinated product was $30.41 \pm 4.01 \mathrm{~nm}$. The size distribution of ZnO NPs for about 86 particles is shown in Fig. S1b.
The phase and purity of the ZnO NPs were characterized by XRD and the diffraction pattern is shown in Fig. S1c. The observed peaks can be indexed to the known hexagonal wurtzite structure of $\mathrm{ZnO}$ according to Joint Committee on Powder Diffraction Standards (JCPDS). No intense peaks of other phases of $\mathrm{ZnO}$ and impurities were found, indicating that the precursor is completely oxidized to the NPs. The high crystallinity of the materials can be manifested from the strong intensity and narrow width of the diffraction peaks.

\subsection{Optimization of the extraction conditions}

Experimental parameters like composition of the NF, volume of the NF, extraction time, stirring rate, $\mathrm{pH}$ of the sample solution and salting out affecting the extraction performance were optimized. The three fungicides were considered to evaluate the extraction capability of the ZnO-NF-SDME and extraction efficiency (\%) of the

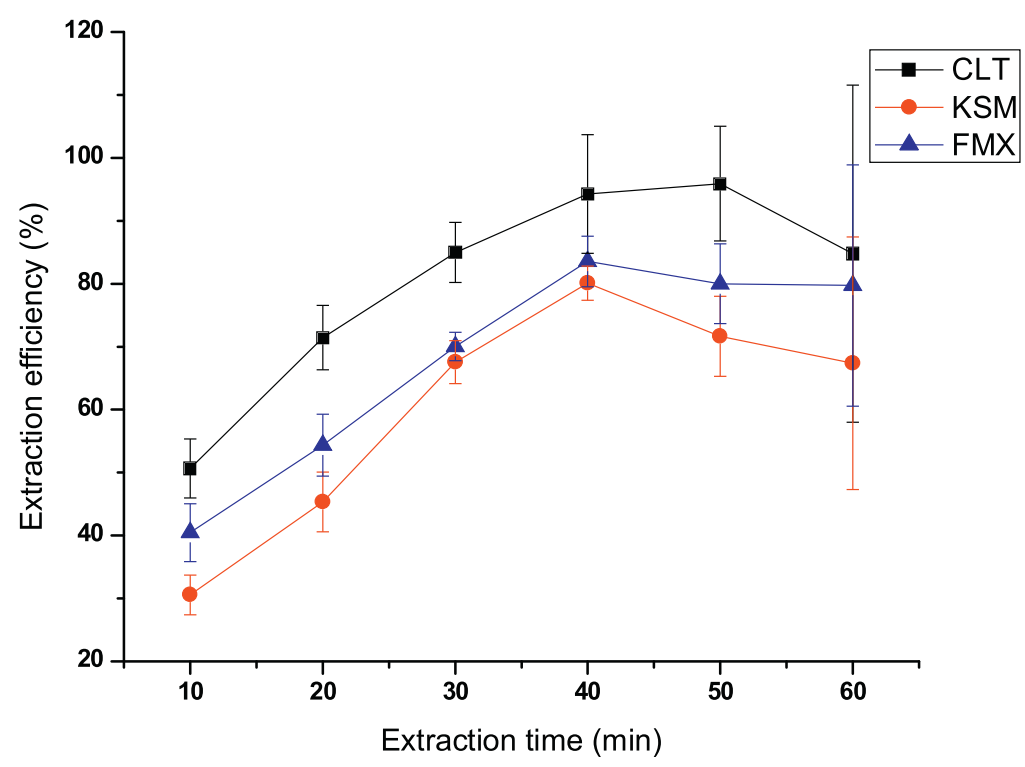

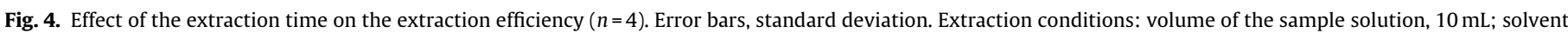
volume, $10 \mu \mathrm{L}$; and stirring rate, $500 \mathrm{rpm}$.

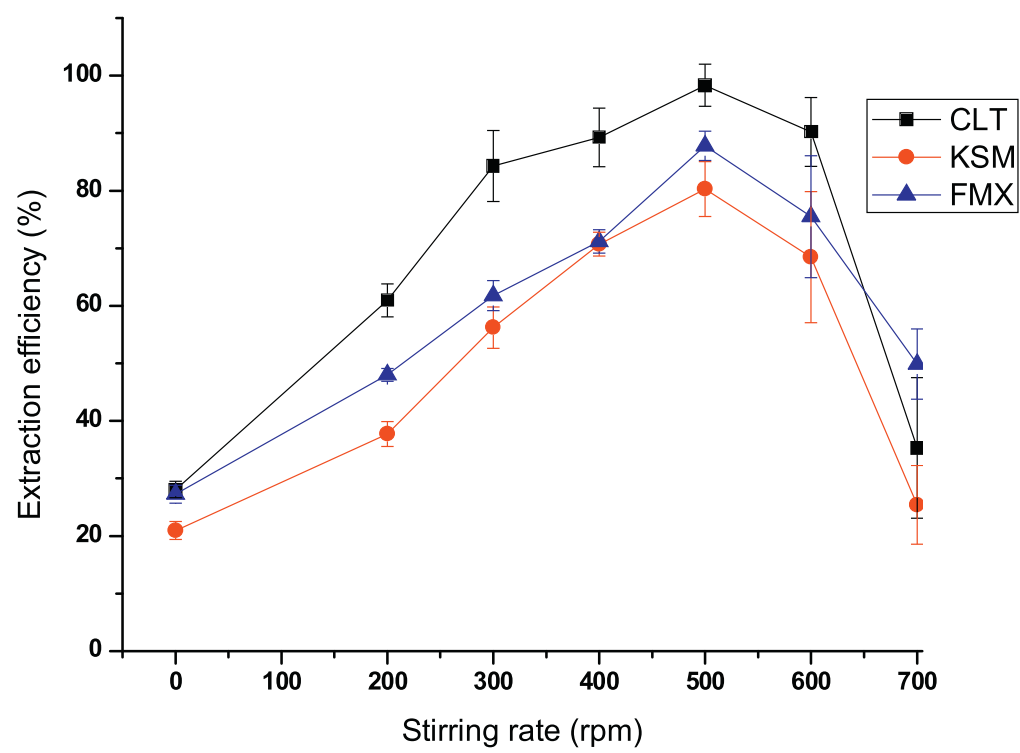

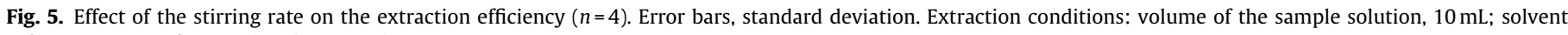
volume, $10 \mu \mathrm{L}$; and extraction time, $40 \mathrm{~min}$. 
analytes was evaluated under different conditions and all experiments were performed in replicate $(n=4)$.

\subsubsection{Effect of composition of the nanofluid}

Four IL-ZnO-NFs were prepared by dispersing various amounts of $\mathrm{ZnO}$ NPs in the IL to investigate the effect of NP composition on the extraction efficiency. Taking [HMIM] $\left[\mathrm{PF}_{6}\right]$ as base fluid, 0.005 , $0.01,0.05$ and $0.1 \%(\mathrm{~m} / \mathrm{m})$ IL-ZnO-NFs were prepared and applied as extraction solvent. The extraction efficiency achieved with the NFs and IL alone is shown in Fig. 2. Among the solvents, 0.01 and $0.005 \%$ NFs exhibited comparable stability and high extraction efficiency than the others. Addition of the NPs to the IL enhanced the extraction efficiency which might be associated to increment in the coefficient of mass transfer due to Brownian motion [32-35]. The high extraction efficiency at lower ZnO NPs composition may be attributed to saturation of the ILs at higher composition which may thwarts the extraction of the fungicides which is in line with the work of Ruiz-Palomero et al. [43]. Therefore, $0.01 \%(\mathrm{~m} / \mathrm{m})$ IL-ZnO-NF was selected as extraction solvent in the subsequent experiments.

\subsubsection{Effect of volume of the extraction solvent}

To examine the effect of volume of the NF on the extraction efficiency, 2, 4, 6, 8 and $10 \mu \mathrm{L}$ of $0.01 \%$ IL-ZnO-NF were subjected to the ZnO-NF-SDME procedure. As shown in Fig. 3, the extraction efficiencies of the fungicides increased with the volume of NF in the range of $2-10 \mu \mathrm{L}$, and then further increase in the solvent volume was found to be incompatible with the current method due to dislodging of the micro-drop. Accordingly, $10 \mu \mathrm{L}$ of the solvent was used as optimal extraction solvent volume in further experiments.

\subsubsection{Effect of the extraction time}

The extraction time was optimized using $10 \mu \mathrm{L}$ of $0.01 \%$ IL$\mathrm{ZnO}-\mathrm{NF}$ by increasing the extraction time from 10 to $60 \mathrm{~min}$ at 10 intervals. In liquid-liquid microextraction, like the current method, extraction efficiency increases with time until equilibrium point $[10,13]$. However, long extraction time could also result in the dissolution of the NF and decrease the extraction efficiency. The effect of extraction time on the extraction efficiency is shown in Fig. 4. As
Table 2

Analytical performances of ZnO-NF-SDME.

\begin{tabular}{|c|c|c|c|c|c|c|c|}
\hline \multirow[t]{2}{*}{ Fungicides } & \multirow{2}{*}{$\begin{array}{l}\text { Linear } \\
\text { range } \\
(\mathrm{ng} / \mathrm{mL})\end{array}$} & \multirow[t]{2}{*}{$R^{2}$} & \multirow[t]{2}{*}{$\begin{array}{l}\text { LOD } \\
(\mathrm{ng} / \mathrm{mL})\end{array}$} & \multirow[t]{2}{*}{$\begin{array}{l}\text { LOQ } \\
(\mathrm{ng} / \mathrm{mL})\end{array}$} & \multirow[t]{2}{*}{$\begin{array}{l}\mathrm{EF} \\
(n=8)\end{array}$} & \multicolumn{2}{|c|}{$\begin{array}{l}\text { RSD (\%) } \\
(n=8)\end{array}$} \\
\hline & & & & & & $\begin{array}{l}\text { Intra- } \\
\text { day }\end{array}$ & $\begin{array}{l}\text { Inter- } \\
\text { day }\end{array}$ \\
\hline CLT & $0.5-100$ & 0.998 & 0.19 & 0.64 & 984 & 4.7 & 6.1 \\
\hline KSM & $0.5-100$ & 0.997 & 0.13 & 0.44 & 846 & 4.8 & 7.0 \\
\hline FMX & $0.5-100$ & 0.996 & 0.19 & 0.63 & 764 & 4.7 & 6.2 \\
\hline
\end{tabular}

depicted in the figure, the extraction efficiency do not improve or even decrease after 40 min of the extraction time which might be due to the dissolution of the NF. Therefore, $40 \mathrm{~min}$ was adopted as the optimized extraction time.

\subsubsection{Effect of the stirring rate}

In general, stirring rate improve extraction efficiency by facilitating exposure of the analytes present in the aqueous solution to the micro-drop [43]. Accordingly, different stirring rates were assessed from 0 to $700 \mathrm{rpm}$ for extraction time of $40 \mathrm{~min}$ and its effect on the extraction efficiency is shown in Fig. 5. It was observed that the extraction efficiency increased with the stirring rate up to $500 \mathrm{rpm}$. After $500 \mathrm{rpm}$, the efficiency decreased due to instability of the micro-drop. Therefore, $500 \mathrm{rpm}$ was selected in the following experiments.

\subsubsection{Effect of the $\mathrm{pH}$ of sample solution}

The $\mathrm{pH}$ effect was investigated in the range of $2-10$ by adjusting $\mathrm{pH}$ of the sample solution with sodium hydroxide or hydrochloric acid solutions. The results showed that the $\mathrm{pH}$ of sample solution demonstrated insignificant effect, though slight increment of extraction efficiency was acquired in 4-7 pH range (Fig. S2). Due to the fact that the analytes under study are stable in neutral and weak acidic media, the fungicides were efficiently extracted to the $\mathrm{NF}$ in this $\mathrm{pH}$ interval. At higher $\mathrm{pH}$ values, destruction of the fungicides were observed which could be attributed to hydrolysis of the

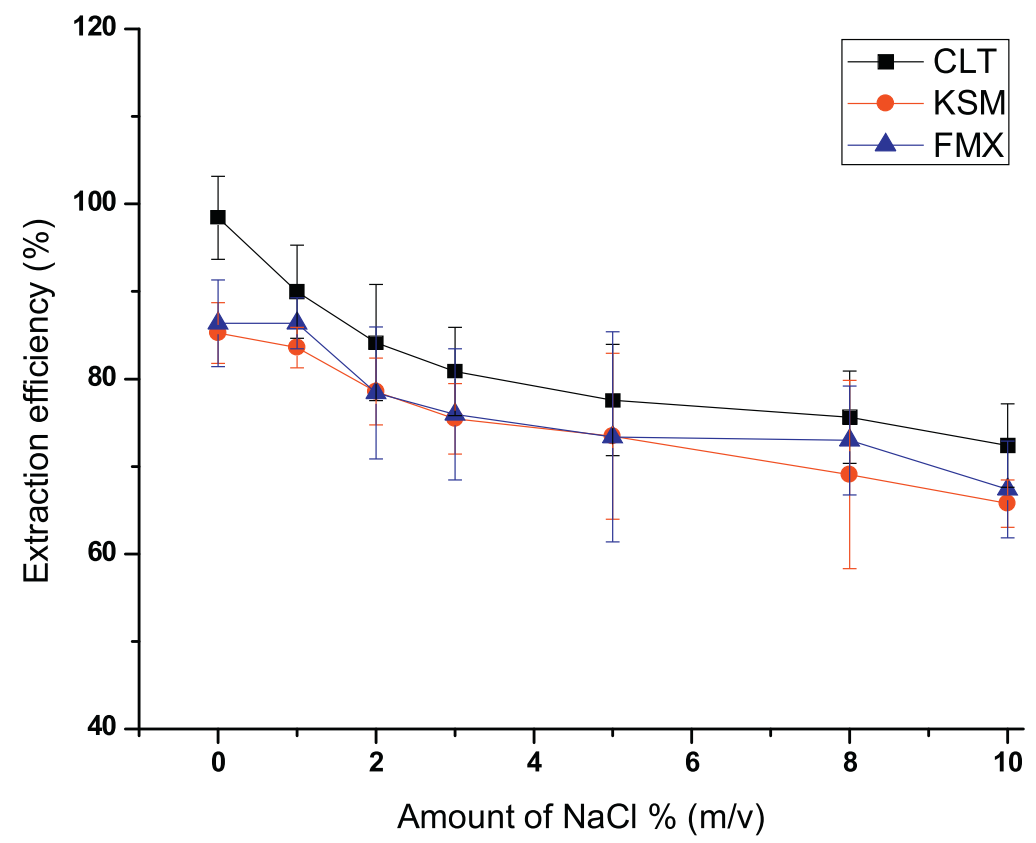

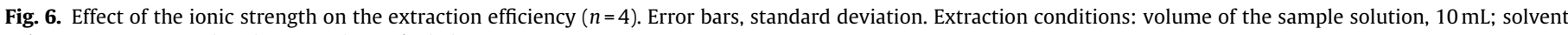
volume, $10 \mu \mathrm{L}$; extraction time, $40 \mathrm{~min}$; and stirring rate, $500 \mathrm{rpm}$. 
analytes in alkaline media [13]. On the basis of these results, $\mathrm{pH} 7$ was selected in the subsequent experiments.

\subsubsection{Effect of ionic strength}

The addition of salt plays a vital role in conventional extraction processes because it can increase an aqueous solution's ionic strength, which decreases the solubility of the analytes in the sample solution as well as improves the extraction efficiency [14]. The influence of ionic strength on $\mathrm{ZnO}$-NF-SDME performance was investigated by adding different amounts of $\mathrm{NaCl}(0-10 \%, w / v)$ to the sample solution. It was found that salt concentration had an opposite effect on the extraction efficiency for the fungicides (Fig. 6). This is possibly due to the instability of the vesicular droplet probably because of bubble formation at higher salt concentrations, and high chloride concentration in the solution may also facilitate the dissolution of the IL which decreases the extraction efficiency [11]. It was also reported that decrease in extraction efficiency at high ionic strength could be caused by precipitation of the fungicides [13]. In addition to these, competitive adsorption might be also the reason for negative effect of the salting out. Hence, no salt was added in the subsequent experiments.

\subsection{Method validation}

After the optimal experimental parameters were determined, the figures of merit were investigated and the results are enumerated in Table 2. It was found that the proposed method exhibits excellent linearity, $R^{2} \geq 0.996$, between the peak area and concentration over the range of $0.5-100 \mathrm{ng} / \mathrm{mL}$ for all the target fungicides. The calculated LODs and LOQs were in the range of $0.13-0.19 \mathrm{ng} / \mathrm{mL}$ and $0.44-0.64 \mathrm{ng} / \mathrm{mL}$, respectively. High enrichment factor (EF), determined as the ratio of the analyte concentration in the microdrop to its concentration in the sample solution, was obtained. The intra-day and inter-day precisions (RSDs, $n=8$ ) investigated using
Table 4

Recovery (\%) values of ZnO-NF-SDME based analysis in real water samples ( $n=6$, mean \pm SD)

\begin{tabular}{llll}
\hline Sample & Fungicide & \multicolumn{2}{l}{ Recovery $(\%)$} \\
\cline { 3 - 4 } & & $5 \mathrm{ng} / \mathrm{mL}$ spiked & $100 \mathrm{ng} / \mathrm{mL}$ spiked \\
\hline River & CLT & $86.8 \pm 6.8$ & $83.8 \pm 3.8$ \\
& KSM & $81.1 \pm 5.4$ & $75.9 \pm 4.9$ \\
\multirow{2}{*}{ Lake } & FMX & $81.8 \pm 6.3$ & $76.7 \pm 3.5$ \\
& CLT & $96.1 \pm 7.8$ & $86.9 \pm 2.3$ \\
\multirow{3}{*}{ Effluent } & KSM & $86.9 \pm 6.4$ & $80.8 \pm 2.9$ \\
& FMX & $81.0 \pm 2.3$ & $76.5 \pm 3.5$ \\
& CLT & $88.5 \pm 6.3$ & $91.0 \pm 3.3$ \\
& KSM & $80.3 \pm 3.9$ & $81.7 \pm 5.0$ \\
& FMX & $81.5 \pm 3.8$ & $80.5 \pm 4.3$ \\
& CLT & $85.9 \pm 6.8$ & $81.2 \pm 2.3$ \\
& KSM & $74.9 \pm 6.9$ & $76.6 \pm 4.5$ \\
& FMX & $75.2 \pm 4.4$ & \\
\hline
\end{tabular}

$10 \mathrm{~mL}$ sample solution containing $5 \mathrm{ng} / \mathrm{mL}$ of each of the fungicides were obtained in the range of $4.7-4.8 \%$ and $6.1-7.0 \%$, respectively.

\subsection{Comparison with other methods}

The current method proposed for extraction and determination of fungicides in various water samples were compared with those of other methods based on HPLC separation (Table 3). As shown, the advantages of the method described here over the other methods include the use $\mathrm{ZnO}-\mathrm{NF}$ as extraction solvent in place of volatile organic solvents, high enrichment factor, and comparable or lower LODs. Therefore, $\mathrm{ZnO}-\mathrm{NF}-\mathrm{SDME}$ is a simple, effective, and relatively environmental benign technique with low solvent and sample consumption that can be used for the preconcentration of fungicides from aqueous samples.

Table 3

Comparison of the current method with other HPLC based methods proposed for the extraction of fungicides in water samples.

\begin{tabular}{|c|c|c|c|c|c|c|c|}
\hline Analytes & Method & Instrument & $\begin{array}{l}\text { Extraction solvent } \\
\text { (volume } \mu \mathrm{L} \text { ) }\end{array}$ & $\begin{array}{l}\text { Extraction time } \\
(\mathrm{min})\end{array}$ & EFs & LODs (ng/mL) & Ref. \\
\hline $\begin{array}{l}\text { Hexaconazole, procymidone, } \\
\text { quinalphos and vinclozolin }\end{array}$ & CSM-LPME ${ }^{\mathrm{a}}$ & LC-UV & Hexane $(200 \mu \mathrm{L})$ & 20 & $55-59$ & $1.1-1.9$ & {$[45]$} \\
\hline $\begin{array}{l}\text { Thiram, metalaxyl, } \\
\text { diethofencarb, myclobutanil } \\
\text { and tebuconazole }\end{array}$ & $\mu \mathrm{SPE}^{\mathrm{b}}$ & HPLC-UVD & - & 40 & - & $0.016-0.086$ & [9] \\
\hline $\begin{array}{l}\text { Myclobutanil, tebuconazole, } \\
\text { triadimenol, hexaconazole }\end{array}$ & DLLME-SFO $^{\mathrm{c}}$ & HPLC-DAD & $\begin{array}{l}\text { 1-Dodecanol }(12 \mu \mathrm{L}) \\
\text { and } 200 \mu \mathrm{L} \text { methanol } \\
\text { (dispersive solvent) }\end{array}$ & 1 & $190-450$ & $0.06-0.1$ & [10] \\
\hline $\begin{array}{l}\text { Thiram, metalaxyl, } \\
\text { diethofencarb, myclobutanil, } \\
\text { and tebuconazole }\end{array}$ & TC-DLLME ${ }^{\mathrm{d}}$ & HPLC-UVD & {$\left[\mathrm{C}_{8} \mathrm{MIM}\right]\left[\mathrm{PF}_{6}\right](55 \mu \mathrm{L})$} & 30 & - & $0.32-0.79$ & {$[11]$} \\
\hline $\begin{array}{l}\text { Azoxystrobin, diethofencarb } \\
\text { and pyrimethanil }\end{array}$ & ISD-DLLME $^{\mathrm{e}}$ & HPLC-MS & $\begin{array}{l}\text { Tolune }(20 \mu \mathrm{L}) \text { and } \\
1000 \mu \mathrm{L} \text { methanol } \\
\text { (dispersive and } \\
\text { demulsified solvent) }\end{array}$ & 2 & $195-239$ & $0.026-0.071$ & {$[12]$} \\
\hline $\begin{array}{l}\text { Carbendazim, fuberidazole, } \\
\text { thiophanate-methyl and } \\
\text { thiophanate }\end{array}$ & SA-LLE ${ }^{\mathrm{f}}$ & HPLC-UVD & Acetonitrile $(2000 \mu \mathrm{L})$ & 5 & - & $0.14-0.38$ & {$[14]$} \\
\hline $\begin{array}{l}\text { Azoxystrobin, diethofencarb, } \\
\text { pyrimethanil and } \\
\text { kresoxim-methyl }\end{array}$ & IL-USA-EME ${ }^{g}$ & HPLC-VWD & {$\left[\mathrm{C}_{8} \mathrm{MIM}\right]\left[\mathrm{PF}_{6}\right](40 \mu \mathrm{L})$} & 15 & $88-137$ & $0.73-2.2$ & [16] \\
\hline $\begin{array}{l}\text { Chlorothalonil, } \\
\text { kresoxim-methyl and } \\
\text { famoxadone }\end{array}$ & ZnO-NF-SDME & HPLC-VWD & ZnO-NF $(10 \mu \mathrm{L})$ & 40 & 764-984 & $0.13-0.19$ & This study \\
\hline
\end{tabular}

a Cone-shaped membrane liquid phase microextraction.

b Micro-solid phase extraction.

c Dispersive liquid-liquid microextraction based on solidification of floating organic droplet.

d Temperature controlled dispersive liquid-liquid microextraction.

e In-syringe demulsified dispersive liquid-liquid microextraction.

f Salting-out assisted liquid-liquid extraction.

$g$ Ultrasound-assisted emulsification microextraction. 

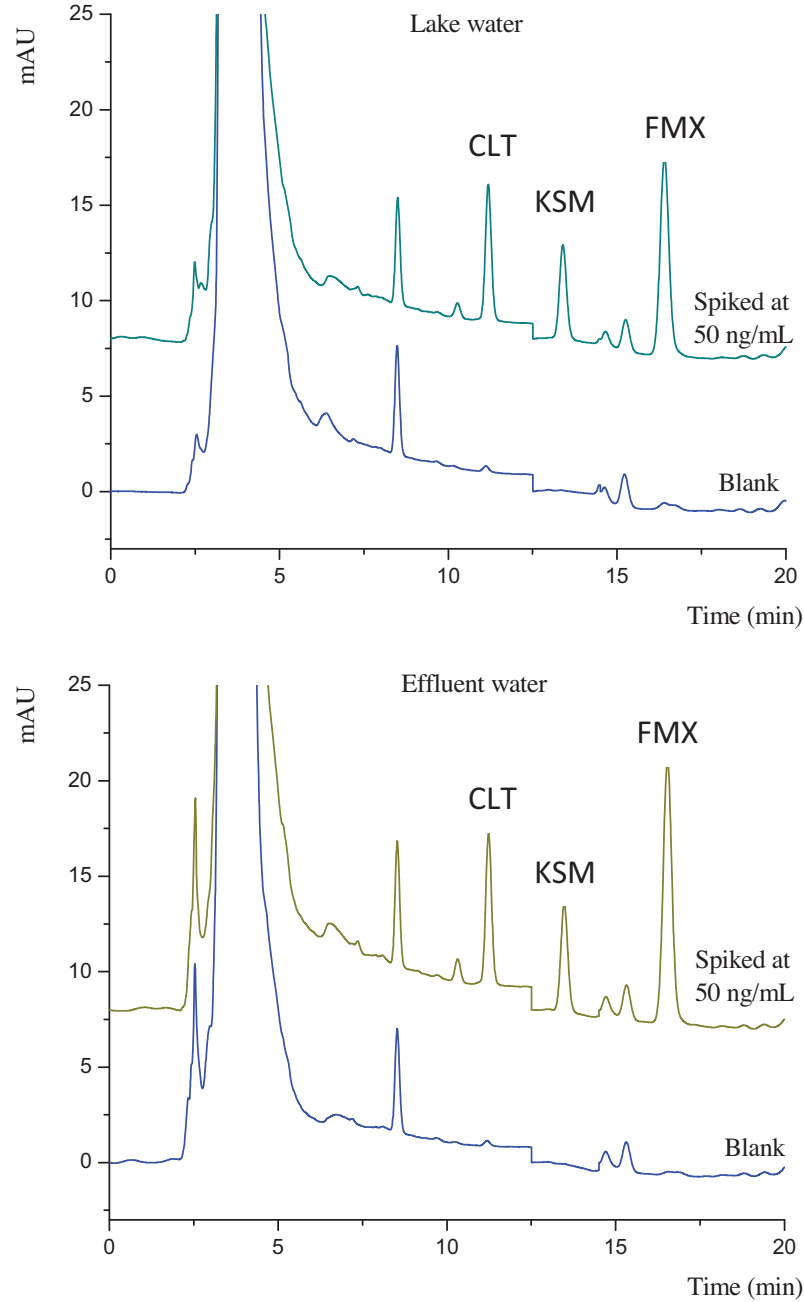
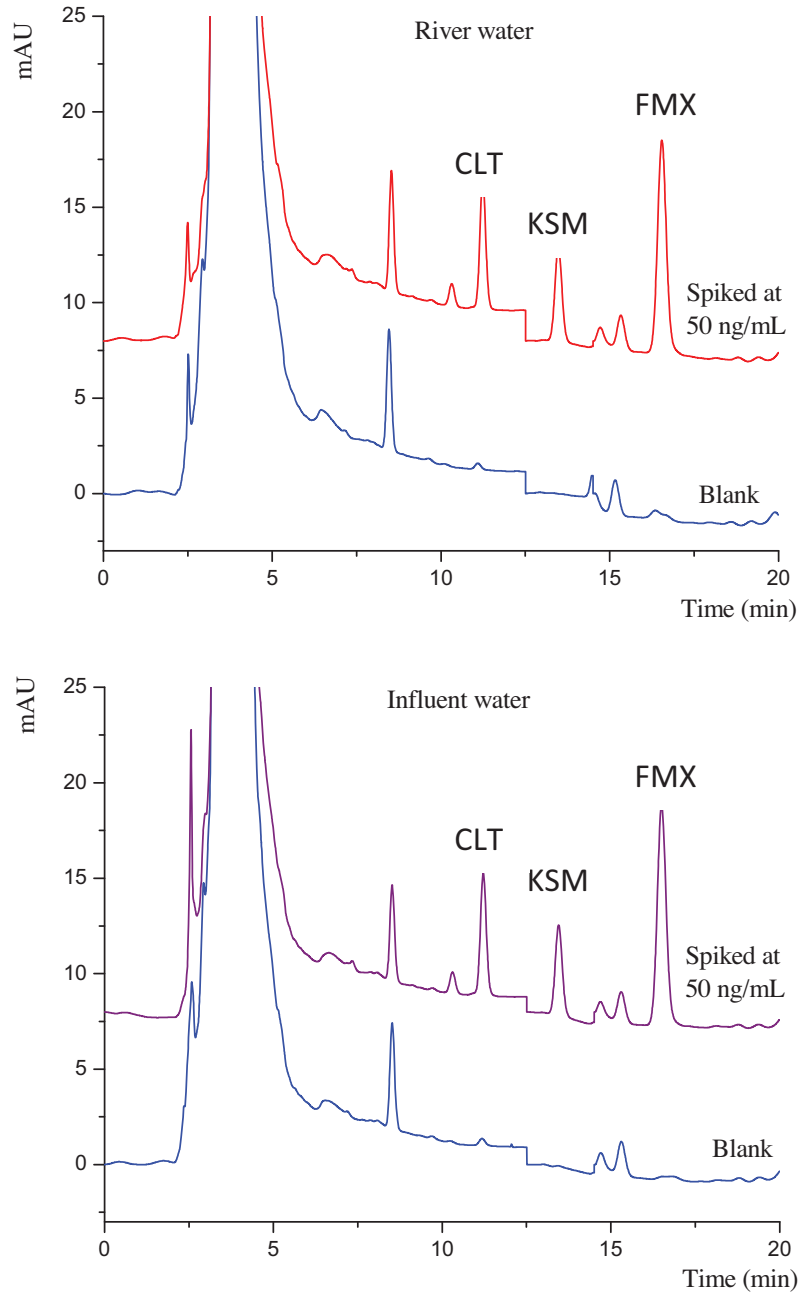

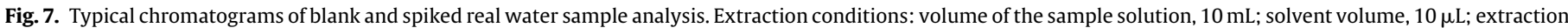
time, $40 \mathrm{~min}$; stirring rate, $500 \mathrm{rpm}$; $\mathrm{pH}$ of the sample solution, 7; and ionic strength, no salt addition.

\subsection{Real sample analysis}

The proposed ZnO-NF-SDME method was applied to the determination of the three analytes in four different types of actual (lake, river, effluent and influent) water samples. In the assayed samples, the target analytes were not detected. Therefore, the samples were spiked with mixed standard solutions and the extraction performance was evaluated to assess the matrix effect. The analytical results are listed in Table 4, and the typical chromatograms of the blank and spiked real water samples are shown in Fig. 7. The recoveries of present method were satisfied in the range of 81.2-96.1\%, $74.9-86.9 \%$ and $75.2-81.8 \%$ for chlorothalonil, kresoxim-methyl and famoxadone, respectively. Hence, the developed method was successfully applied and can be used as alternative technique for analysis of multi residue fungicides in water samples.

\section{Conclusions}

In the current study, effective and risk-free ZnO-NF-SDME preconcentration technique for HPLC-VWD analysis was developed for the determination of fungicides in water samples. ZnO-NF obtained through dispersion of ZnO NPs in [HMIM] $\left.\mathrm{PF}_{6}\right]$ is proposed as an extraction solvent in this microextraction approach. Based on the developed method, effective extraction of chlorothalonil, kresoxim-methyl and famoxadone fungicides in real water samples (river, lake, effluent and influent) were achieved with reasonable linearity, good precisions, and satisfactory relative recoveries. The potentials of the method described here include instead of volatile organic solvents, NF was used as the extraction solvent, which is relatively safe and environmentally compatible, high EF, low LOD, precise, and acceptable recovery values were obtained which indicate its high utility. In conclusion, IL-ZnO-NF based ZnO-NF-SDME presents a simple, effective, and relatively environmental benign technique with low sample consumption that can be used for the preconcentration of fungicides from water samples.

\section{Acknowledgements}

This work was supported by the Strategic Priority Research Program of the Chinese Academy of Sciences (XDB14020101), and the Chinese Academy of Sciences (YSW2013A01, YSW2013B01). Meseret Amde acknowledges the support of CAS-TWAS President's Fellowship for his PhD study.

\section{Appendix A. Supplementary data}

Supplementary data associated with this article can be found, in the online version, at http://dx.doi.org/10.1016/j.chroma. 2015.03.049. 


\section{References}

[1] L. Ruiz-Gil, R. Romero-Gonzalez, A. Garrido Frenich, J.L. Martinez Vidal, Determination of pesticides in water samples by solid phase extraction and gas chromatography tandem mass spectrometry, J. Sep. Sci. 31 (2008) 151-161.

[2] A.O. Olsson, S.E. Baker, J.V. Nguyen, L.C. Romanoff, S.O. Udunka, R.D. Walker, K.L. Flemmen, D.B. Barr, A liquid chromatography-tandem mass spectrometry multiresidue method for quantification of specific metabolites of organophosphorus pesticides, synthetic pyrethroids, selected herbicides, and DEET in human urine, Anal. Chem. 76 (2004) 2453-2461.

[3] P. Sukul, M. Spiteller, Persistence, fate, and metabolism of [14C]Metalaxyl in typical Indian soils, J. Agric. Food Chem. 49 (2001) 2352-2358.

[4] C. Saínchez-Brunete, E. Miguel, J.L. Tadeo, M ultiresidue analysis of fungicides in soil by sonication-assisted extraction in small columns and gas chromatography, J. Chromatogr. A 976 (2002) 319-327.

[5] C. Goncalves, M.F. Alpendurada, Assessment of pesticide contamination in soil samples from an intensive horticulture area, using ultrasonic extraction and gas chromatography-mass spectrometry, Talanta 65 (2005) 1179-1189.

[6] EU, Quality of water intended for human consumption, Off. J. Eur. Commun. L330 (1998) 32-54.

[7] D.A. Lambropoulou, I.K. Konstantinou, T.A. Albanis, Determination of fungicides in natural waters using solid-phase microextraction and gas chromatography coupled with electron-capture and mass spectrometric detection, J. Chromatogr. A 893 (2000) 143-156.

[8] Z. Li, M. Hou, S. Bai, C. Wang, Z. Wang, Extraction of imide fungicides in water and juice samples using magnetic graphene nanoparticles as adsorbent followed by their determination with gas chromatography and electron capture detection, Anal. Sci. 29 (2013) 325-331.

[9] Y. Huang, Q. Zhou, G. Xie, Development of sensitive determination method for fungicides from environmental water samples with Titanate nanotube array micro-solid phase extraction prior to high performance liquid chromatography, Chemosphere 90 (2013) 338-343.

[10] C. Wang, Q. Wu, C. Wu, Z. Wang, Application of dispersion-solidification liquid-liquid microextraction for the determination of triazole fungicides in environmental water samples by high-performance liquid chromatography, J. Hazard. Mater. 185 (2011) 71-76.

[11] Y. Gao, Q. Zhou, G. Xie, Z. Yao, Temperature-controlled ionic liquid dispersive liquid-phase microextraction combined with HPLC with ultraviolet detector for the determination of fungicides, J. Sep. Sci. 35 (2012) 3569-3574.

[12] Y. Xia, M. Cheng, F. Guo, X. Wang, J. Cheng, In-syringe demulsified dispersive liquid-liquid microextraction and high performance liquid chromatography-mass spectrometry for the determination of trace fungicides in environmental water samples, Anal. Chim. Acta 724 (2012) 47-53.

[13] H.-J. Pan, W.-H. Ho, Determination of fungicides in water using liquid phase microextraction and gas chromatography with electron capture detection, Anal. Chim. Acta 527 (2004) 61-67.

[14] Y. Wen, J. Li, F. Yang, W. Zhang, W. Li, C. Liao, L. Chen, Salting-out assisted liquid-liquid extraction with the aid of experimental design for determination of benzimidazole fungicides in high salinity samples by high-performance liquid chromatography, Talanta 106 (2013) 119-126.

[15] J. Cheng, Y. Xia, Y. Zhou, F. Guo, G. Chen, Application of an ultrasound-assisted surfactant-enhanced emulsification microextraction method for the analysis of diethofencarb and pyrimethanil fungicides in water and fruit juice samples, Anal. Chim. Acta 701 (2011) 86-91.

[16] P. Liang, F. Wang, Q. Wan, Ionic liquid-based ultrasound-assisted emulsification microextraction coupled with high performance liquid chromatography for the determination of four fungicides in environmental water samples, Talanta 105 (2013) 57-62.

[17] T. Tang, K. Qian, T. Shi, F. Wang, J. Li, Y. Cao, Determination of triazole fungicides in environmental water samples by high performance liquid chromatography with cloud point extraction using polyethylene glycol 600 monooleate, Anal. Chim. Acta 680 (2010) 26-31.

[18] A. Spietelun, L. Marcinkowski, M. de la Guardia, J. Namiesnik, Green aspects, developments and perspectives of liquid phase microextraction techniques, Talanta 119 (2014) 34-45.

[19] C.J. Welch, N. Wu, M. Biba, R. Hartman, T. Brkovic, X. Gong, R. Helmy, W. Schafer, J. Cuff, Z. Pirzada, Greening analytical chromatography, Trends Anal. Chem. 29 (2010) 667-680.

[20] Z.L. Seow, A.S. Wong, V. Thavasi, R. Jose, S. Ramakrishna, G.W. Ho, Controlled synthesis and application of $\mathrm{ZnO}$ nanoparticles, nanorods and nanospheres in dye-sensitized solar cells, Nanotechnology 20 (2009) 045604

[21] M. Ghaedi, G. Negintaji, H. Karimi, F. Marahel, Solid phase extraction and removal of brilliant green dye on zinc oxide nanoparticles loaded on activated carbon: new kinetic model and thermodynamic evaluation, J. Ind. Eng. Chem. 20 (2014) 1444-1452.

[22] M. Ghaedi, M. Ghayedi, S.N. Kokhdan, R. Sahraei, A. Daneshfar, Palladium, silver, and zinc oxide nanoparticles loaded on activated carbon as adsorbent for removal of bromophenol red from aqueous solution, J. Ind. Eng. Chem. 19(2013) 1209-1217.

[23] M.M. Rahman, S.B. Khan, H.M. Marwani, A.M. Asiri, K.A. Alamry, M.A. Rub, A Khan, A.A.P. Khan, N. Azum, Facile synthesis of doped ZnO-CdO nanoblocks as solid-phase adsorbent and efficient solar photo-catalyst applications, J. Ind. Eng. Chem. 20 (2014) 2278-2286.

[24] Z. Wang, G. Meng, Z. Huang, Z. Li, Q. Zhou, Ag-nanoparticle-decorated porous $\mathrm{ZnO}$-nanosheets grafted on a carbon fiber cloth as effective SERS substrates, Nanoscale 6 (2014) 15280-15285.

[25] R. Jalal, E.K. Goharshadi, M. Abareshi, M. Moosavi, A. Yousefi, P. Nancarrow, ZnO nanofluids: green synthesis, characterization, and antibacterial activity, Mater. Chem. Phys. 121 (2010) 198-201.

[26] F. Niyaghi, K.R. Haapala, S.L. Harper, M.C. Weismiller, Stability and biological responses of zinc oxide metalworking nanofluids ( $\mathrm{ZnO} \mathrm{MWnF}^{\mathrm{TM}}$ ) using dynamic light scattering and zebrafish assays, Tribol. Trans. 57 (2014) 730-739.

[27] B.K. Sonage, P. Mohanan, Characterization of zinc oxide nanoparticles used for preparation of nanofluids, Procedia Mater. Sci. 5 (2014) 1160-1164.

[28] M.J. Pastoriza-Gallego, L. Lugo, D. Cabaleiro, J.L. Legido, M.M. Piñeiro, Thermophysical profile of ethylene glycol-based ZnO nanofluids, J. Chem. Thermodyn. 73 (2014) 23-30.

[29] S.U.S. Choi, ASME International Mechanical Engineering Congress \& Exposition, San Francisco, USA, 1995, pp. 99-105.

[30] Z. Haddad, C. Abid, H.F. Oztop, A. Mataoui, A review on how the researchers prepare their nanofluids, Int. J. Therm. Sci. 76 (2014) 168-189.

[31] K. Mawatari, Y. Kazoe, H. Shimizu, Y. Pihosh, T. Kitamori, Extendednanofluidics: fundamental technologies, unique liquid properties, and application in chemical and bio analysis methods and devices, Anal. Chem. 86 (2014) 4068-4077.

[32] S. Krishnamurthy, P. Bhattacharya, P.E. Phelan, Enhanced mass transport in nanofluids, Nano Lett. 6 (2006) 419-423.

[33] X. Fang, Y. Xuan, Q. Li, Experimental investigation on enhanced mass transfer in nanofluids, Appl. Phys. Lett. 95 (2009) 203108.

[34] J. Saien, H. Bamdadi, Mass transfer from nanofluid single drops in liquid-liquid extraction process, Ind. Eng. Chem. Res. 51 (2012) 5157-5166.

[35] A. Bahmanyar, N. Khoobi, M.R. Mozdianfard, H. Bahmanyar, The influence of nanoparticles on hydrodynamic characteristics and mass transfer performance in a pulsed liquid-liquid extraction column, Chem. Eng. Process. 50 (2011) 1198-1206.

[36] A. Bahmanyar, N. Khoobi, M.M.A. Moharrer, H. Bahmanyar, Mass transfer from nanofluid drops in a pulsed liquid-liquid extraction column, Chem. Eng. Res. Des. 92 (2014) 2313-2323.

[37] P. Wasserscheid, T. Welton, Ionic Liquids in Synthesis, WILEY-VCH Verlag GmbH \& Co. KGaA, 2008.

[38] B. Peric, J. Sierra, E. Marti, R. Cruanas, M.A. Garau, A comparative study of the terrestrial ecotoxicity of selected protic and aprotic ionic liquids, Chemosphere 108 (2014) 418-425.

[39] P. Mester, M. Wagner, P. Rossmanith, Antimicrobial effects of short chained imidazolium-based ionic liquids-influence of anion chaotropicity, Ecotoxicol. Environ. Saf. 111 (2015) 96-101.

[40] M. Markiewicz, M. Piszora, N. Caicedo, C. Jungnickel, S. Stolte, Toxicity of ionic liquid cations and anions towards activated sewage sludge organisms from different sources - consequences for biodegradation testing and wastewater treatment plant operation, Water Res. 47 (2013) 2921-2928.

[41] J.-F. Liu, G.-B. Jiang, J.-F. Liu, J.Å. Jönsson, Application of ionic liquids in analytical chemistry, Trends Anal. Chem. 24 (2005) 20-27.

[42] F. Pena-Pereira, L. Marcinkowski, A. Kloskowski, J. Namiesnik, Silica-based ionogels: nanoconfined ionic liquid-rich fibers for headspace solid-phase microextraction coupled with gas chromatography-barrier discharge ionization detection, Anal. Chem. 86 (2014) 11640-11648.

[43] C. Ruiz-Palomero, M.L. Soriano, M. Valcarcel, Ternary composites of nanocellulose, carbonanotubes and ionic liquids as new extractants for direct immersion single drop microextraction, Talanta 125 (2014) 72-77.

[44] R.R. Gandhi, S. Gowri, J. Suresh, M. Sundrarajan, Ionic liquids assisted synthesis of $\mathrm{ZnO}$ nanostructures: controlled size, morphology and antibacterial properties, J. Mater. Sci. Technol. 29 (2013) 533-538.

[45] M.M. Sanagi, H.H. See, W.A. Ibrahim, A.A. Naim, Determination of pesticides in water by cone-shaped membrane protected liquid phase microextraction prior to micro-liquid chromatography, J. Chromatogr. A 1152 (2007) 215-219. 